\title{
Conscious sedation combined with local anaesthesia for vaginal hysterectomy : a pilot study
}

S. Hadzilias ${ }^{1}$, E. Stamatakis ${ }^{1}$, T. Gregoriadis², T. Papalios², K. Kalopita', S. Athanasiou², D.

Valsamidis $^{1}$

${ }^{1}$ Alexandra General Hospital, Anaesthesiology and Pain Department, Athens, Greece

${ }^{2}$ National and Kapodistrian University of Athens- Alexandra Hospital, Urogynaecology Unit- 1st

Department of Obstetrics and Gynaecology, Athens, Greece

\section{Backoround and aims}

Several studies have suggested numerous advantages of local anaesthesia over both regional and general anaesthesia techniques. The aim of this study was to evaluate and describe the safety and feasibility of performing vaginal prolapse surgery under local anaesthesia and conscious sedation using dexmetomidine.

\section{Methods}

We studied 19 patients ASA II-III, aged 55- 80 years old presenting with stage $>=3$ uterine prolapse and undergoing vaginal hysterectomy and pelvic floor repair. All procedures were performed with pudendal nerve block and local infiltration under conscious sedation. Patients demographics, duration of surgery, amount of local anaesthetic used, hospital stay, urinary retention, the need for conversion to general anaesthesia and complication rates were recorded. All patients were premedicated with midazolam 0.02 $\mathrm{mg} / \mathrm{kg}$ and a bolus dose of $1 \mu \mathrm{g} / \mathrm{kg}$ dexmedetomidine for 10 minutes followed by an infusion of 0.7 $1 \mu \mathrm{g} / \mathrm{kg} / \mathrm{h}$. The anaesthetic solution consisted of $20 \mathrm{ml}$ lidocaine $2 \%$ and $40 \mathrm{ml}$ ropivacaine $0.5 \%$ in 1:200000 adrenaline. A score of 2-3 on the Ramsay Sedation Scale was maintained throughout surgery. Hemodynamic variables and pain (Visual Analogue Scale 0-10) were recorded during surgery. Postoperative pain, analgesia requirements, nausea and vomiting were also assessed. Patient satisfaction was assessed using a five-point likert scale. Level of sedation was measured by a $10-\mathrm{cm}$ VAS scale.

\section{Resullis}

One patient was converted to general anaesthesia. Pain intensity at rest and the level of sedation at $2,8,12$ and 24 hours postoperatively were $0,0.3 \pm 0.8,0.8 \pm 1.9,0.5 \pm 1.1$ and $4.3 \pm 1.3,2.8 \pm 1.8$, $2 \pm 1.2,1.2 \pm 0.7$ respectively. All patients were fully mobilised within 3 hours. $18 / 19(94 \%)$ of the patients reported being very satisfied and $1 / 19(5 \%)$ reported to being satisfied with this type of anesthesia. None $(0 \%)$ reported to be dissatisfied. The mean hospital stay was $3.5 \pm 1.5$ days. Surgical time was $107.5 \pm 23.4$ minutes. No adverse events such as bradycardia or hypotension were noted.

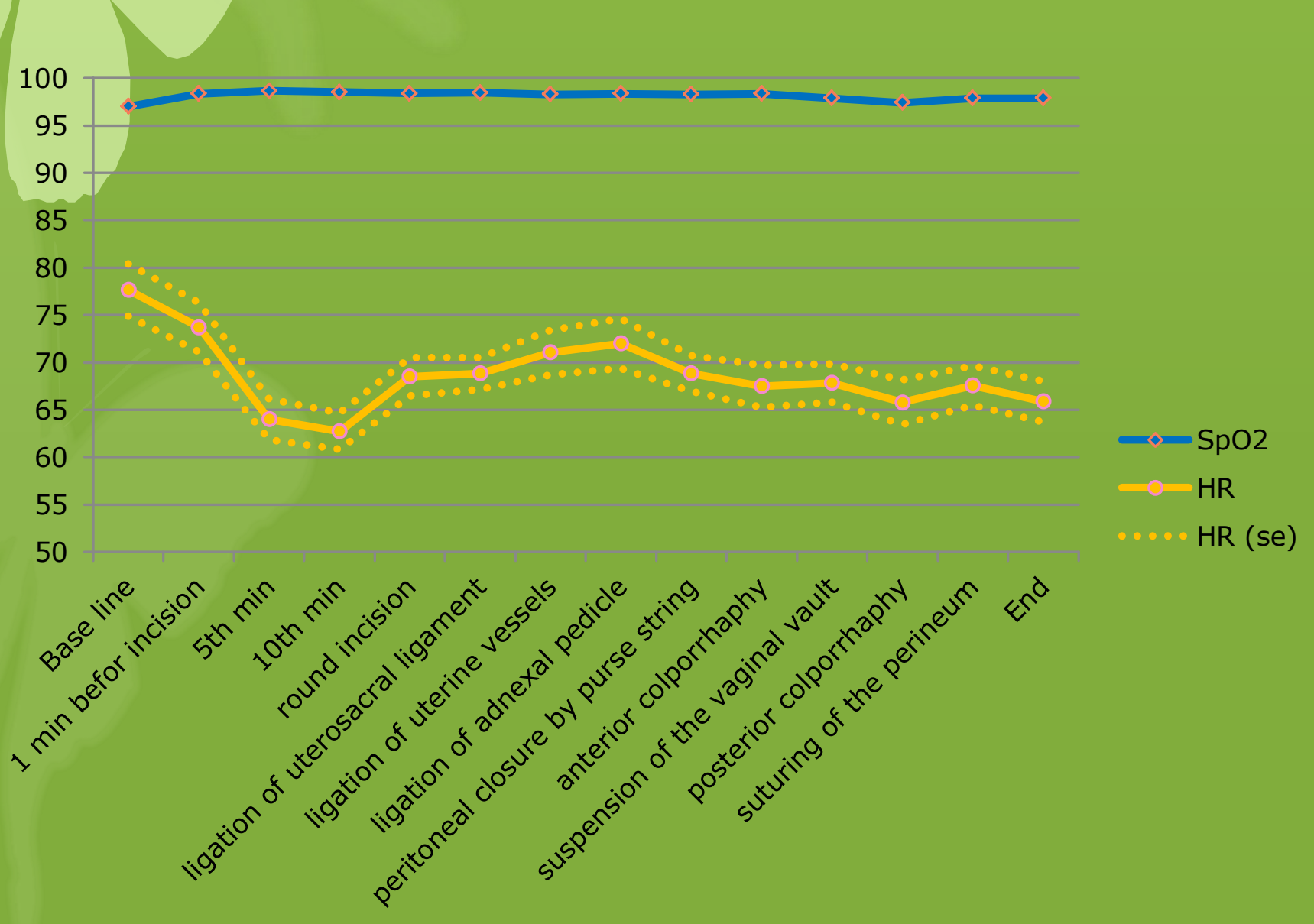

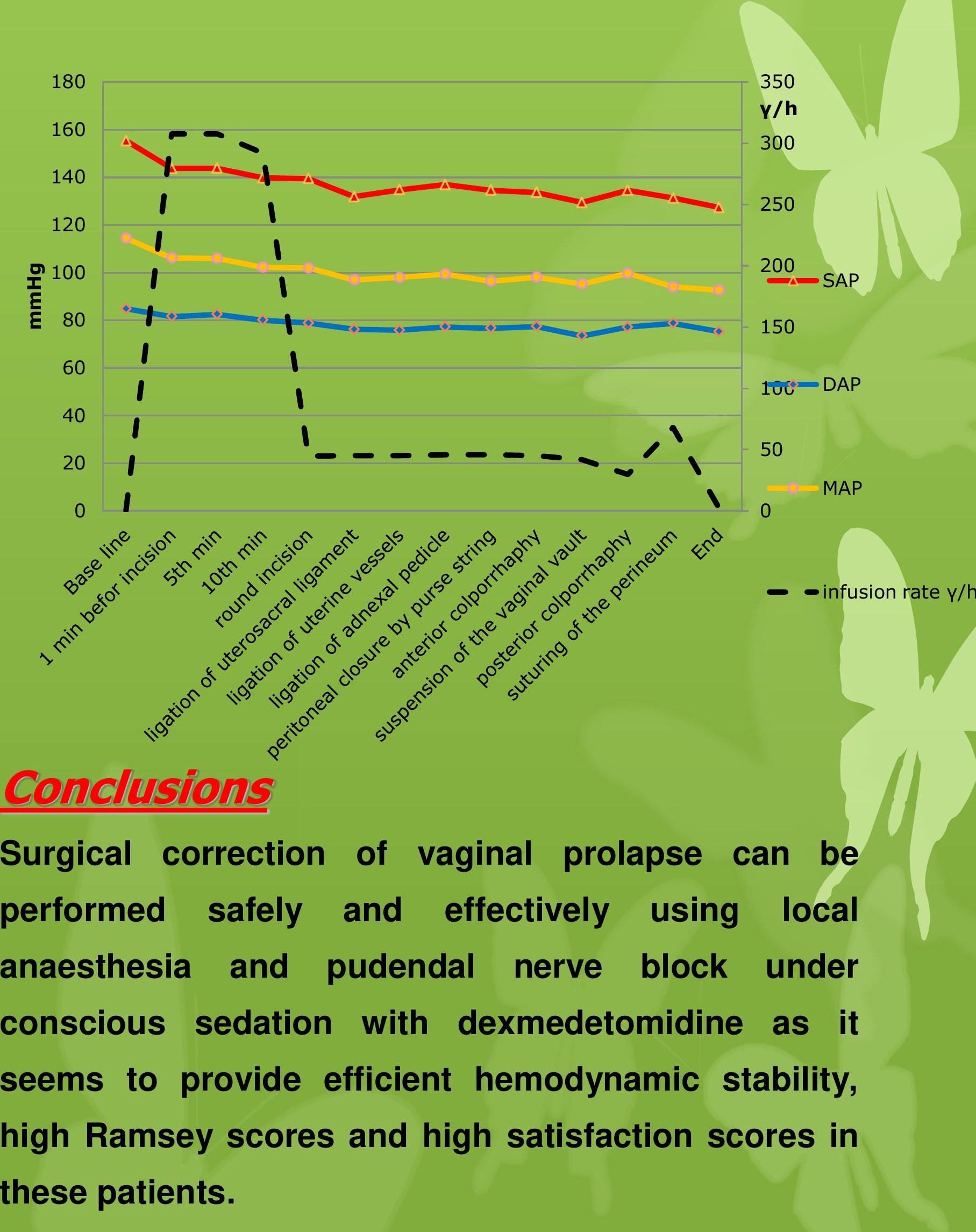

